\title{
Trauma and Emergency Surgery-a Career with Passion
}

\author{
Subodh Kumar ${ }^{1}$ (D) \\ Received: 8 May 2021 / Accepted: 11 May 2021 / Published online: 13 May 2021 \\ (C) Association of Surgeons of India 2021
}

Trauma or its synonym injury is a disease and it can very well be explained by Haddon's matrix [1]. Trauma is responsible for high morbidity and mortality. Worldwide, approximately 1.3 million people are killed in road traffic crashes and 78 million are injured every year [2]. The National Crime Records Bureau (NCRB) reported that 154,732 people died on Indian roads due to trauma in 2019 [3]. Trauma-related mortality affects mainly the young population in the $3^{\text {rd }}$ and $4^{\text {th }}$ decades of life. It is not only loss of life but also loss to a family and society at large and loss of livelihood with financial burden on both family and society. There is an urgent need to reduce morbidity and mortality due to trauma and every effort must be made at individual, institutional, state, and national levels to achieve this goal.

There is a need to develop a dedicated and robust trauma care system in the country which should include pre-hospital care, in-hospital acute care, in-hospital definitive care, and rehabilitation program. Trauma care system is a concept of which the trauma centre is an integral part. Standalone trauma centres are difficult to justify because trauma centers require instant services of other departments including gynaecology and paediatrics and such clinical and molecular diagnostic services cannot be duplicated. Thus, there is a need to develop, strengthen, and integrate a trauma care facility within the existing health care facilities. Hence, there is an urgent need to produce a special cadre of surgeons who are trained in managing trauma patients and general surgical emergencies and in surgical critical care. In 2003, the American Association for the Surgery of Trauma (AAST) defined acute care surgery (ACS) as a speciality with three essential components - trauma, critical care, and emergency surgery with an aim to increase the scope of "trauma surgeons" [4]. In European countries, similar concept of ACS is practiced as

Subodh Kumar

subodh6@gmail.com; subodh6@aiims.edu

1 Division of Trauma Surgery \& Critical Care, JPN Apex Trauma Center, All India Institute of Medical Sciences, New Delhi 110029 , India trauma and emergency surgery (TES) [5]. Both ACS and TES are interchangeable. Since trauma surgeons are trained to work during odd hours with limited resources, they can manage general surgical emergencies more efficiently. In addition, the literature supports the concept of ACS or TES surgeons and emphasise that, in addition to trauma and emergency surgeries, elective general surgery should also be an essential component of training of acute care surgeons [6, 7]. On comparing the surgical practice of TES surgeons and elective practice general surgery (ELEC) surgeons, it was found that TES surgeons admitted more patients and performed more after-hour operations compared with their ELES colleagues [8]. Nowadays, more and more general surgeons are opting for elective surgeries and, as a result, non-traumatic surgical emergencies are being neglected. Operative experience of dedicated trauma surgeons is declining because more and more trauma patients are being managed non-operatively and because of better pre-hospital care [9]. Operative workload is critical for trauma surgeons to maintain their operative skills and promoting trauma surgery as a career option for surgical trainees. It has been recommended that general surgery emergencies should be included in the training program of trauma surgery [9]. Moreover, combining the trauma and non-trauma surgical emergencies improved the overall satisfaction of trauma surgeons [10].

General surgery is a broad speciality, and during the early twentieth century, general surgeons used to perform all kind of surgical procedures. But over the decades, many subspecialities have been carved out such as neurosurgery, cardiothoracic surgery, plastic surgery, urology, gastrointestinal surgery, paediatric surgery, and onco-surgery to provide dedicated patient care, focused research, and training in these areas. Similarly, ACS/TES has been recognised as a subspeciality worldwide. But awareness of ACS as a speciality is lacking among medical students. In a survey, 54\% medical students were not aware about ACS as a speciality [11]. The need for ACS education in the form of clinical rotation of medical students has been emphasised [12]. Currently, three postgraduate training programs in the field of trauma and emergency surgery are available in India. The National 
Medical Commission (erstwhile Medical Council of India) recognised the need of a specialist trained in trauma and emergency surgery and developed a curriculum of a postgraduate course in traumatology and surgery in 2016 [13]. The National Board of Examination (NBE) in Medical Sciences, a national body which awards degrees in various specialities, is running a post-doctoral fellowship program in Trauma and Acute Care Surgery [14]. The All India Institute of Medical Sciences (AIIMS), New Delhi, an autonomous institution, started a post-doctoral program known as Master in Chirurgiae (M.Ch.) in Trauma Surgery and Critical Care (TSCC) in the year 2016 with a mandate to produce trauma surgeons who can deal with all types of life and limbthreatening injuries including orthopaedic and neurosurgical trauma [15]. Subsequently, other institutes such as AIIMS Rishikesh, AIIMS Jodhpur, and AIIMS Patna have also started an M.Ch. program in TSCC. Therefore, a separate cadre of TES or ACS surgeons is required to provide effective patient care, perform quality research, and impart training to surgical residents in the field of trauma and emergency surgery. Collectively, we should leave no stone unturned to make this speciality an attractive career option for young doctors.

"Keep training and keep learning until you get it right."

\section{Declarations}

Conflict of Interest The author declares no competing interests.

\section{References}

1. Bocage C, Mashalla Y, Motshome P, Fane O, Masilo-Nkhoma L, Mathiba O, Mautle E, Kuiperij B, Mmusi T, Holmes JH, Tam V, Barg FK, Wiebe DJ (2020) Applying the Haddon matrix conceptual model to guide motor vehicle crash injury research and prevention in Botswana. Afr J Emerg Med 10(Suppl 1):S38--S43
2. Paniker J, Graham SM, Harrison JW (2015) Global Trauma: the great divide. SICOT J 1:19

3. National Crime Records Bureau. https://ncrb.gov.in/sites/default/ files/Chapter-1A-Traffic-Accidents_2019. Accessed on 2 April 2021.

4. The American association for the Surgery of Trauma. https://www. aast.org/acute-care-surgery-overview. Accessed on 2 April 2021.

5. Tugnoli G, Casali M, Villani S, Biscardi A, Baldoni F (2004) Trauma and emergency surgery. Organization and surgeons experience. Ann Ital Chir 75:407-413

6. Pryor JP, Reilly PM, Schwab CW, Kauder DR, Dabrowski GP, Gracias VH, Braslow B, Gupta R (2004) Integrating emergency general surgery with a trauma service: impact on the care of injured patients. J Trauma 57:467-471

7. Feliciano DV, Mattox KL, Moore EE (2021) TRAUMA. McGrawHill Professional, New York

8. Scherer LA, Battistella FD (2004) Trauma and emergency surgery: an evolutionary direction for trauma surgeons. J Trauma 56:7-12

9. Schuster KM, Lopez PP, Greene T, Wheeler K, Soffer D, Habib F, Cohn SM, Schulman CI (2008) How can trauma surgeons maintain their operative skills? J Trauma 65:387-389

10. Kim PK, Dabrowski GP, Reilly PM, Auerbach S, Kauder DR, Schwab CW (2004) Redefining the future of trauma surgery as a comprehensive trauma and emergency general surgery service. J Am Coll Surg 199:96-101

11. Montgomery SC, Privette AR, Ferguson PL, Mirdamadi M, Fakhry SM (2015) Inadequately marketing our brand: medical student awareness of acute care surgery. J Trauma Acute Care Surg 79: 858-864

12. Chai AL, Matsushima K, Strickland M, Sullivan ME, Inaba K, Demetriades D (2021) A nationwide survey study on medical student experience in acute care surgery. J Surg Res 261:146-151

13. National Medical Commission. https://www.nmc.org.in/wpcontent/uploads/2019/09/MS-Traumatology-surgery. Accessed on 2 April, 2021.

14. National Board of Examination. https://natboard.edu.in. Accessed 2 April 2021.

15. All India Institute of Medical Sciences, New Delhi. www.aiims. edu. Accessed on 2 April 2021.

Publisher's Note Springer Nature remains neutral with regard to jurisdictional claims in published maps and institutional affiliations. 